\title{
Folding Thermodynamics and Kinetics of YNMG RNA Hairpins: Specific Incorporation of 8-bromoguanosine Leads to Stabilization by Enhancement of the Folding Rate: Supporting Information
}

David J. Proctor, ${ }^{\dagger}$ Hairong Ma, Elżbieta Kierzek, ${ }^{\perp}$ Ryszard Kierzek,,$^{\S}$ Martin Gruebele, ${ }^{* \neq}$ and Philip C. Bevilacqua ${ }^{*,+}$

Contribution from the Department of Chemistry, The Pennsylvania State University, University Park, Pennsylvania 16802, and the Center for Biophysics and Computational Biology, University of Illinois at Urbana-Champaign, Illinois 61801, and the Department of Chemistry, University of Rochester, Rochester, New York 14627, and Institute of Bioorganic Chemistry, Polish Academy of Sciences, Z. Noskowskiego 12/14, 61-704 Poznañ, Poland

Running title: RNA Hairpin Stabilization by Folding Rate Enhancement

*To whom correspondence should be addressed. Phone: (814) 863-3812, P.C.B.; (217) 333-1624, M.G. Fax: (814) 863-8403, P.C.B.; (217) 244-3186, M.G. E-mail: pcb@chem.psu.edu; gruebele@scs.uiuc.edu

\section{Contents:}

\section{Supplemental Figure 1 \\ 2. Supplemental Figure 2 \\ 3. Supplemental Figure 3}

\footnotetext{
${ }^{\dagger}$ Department of Chemistry, The Pennsylvania State University.

${ }^{\ddagger}$ Center for Biophysics and Computational Biology, University of Illinois at Urbana-Champaign.

${ }^{\perp}$ Department of Chemistry, University of Rochester.

$\S$ Institute of Bioorganic Chemistry, Polish Academy of Sciences.
} 

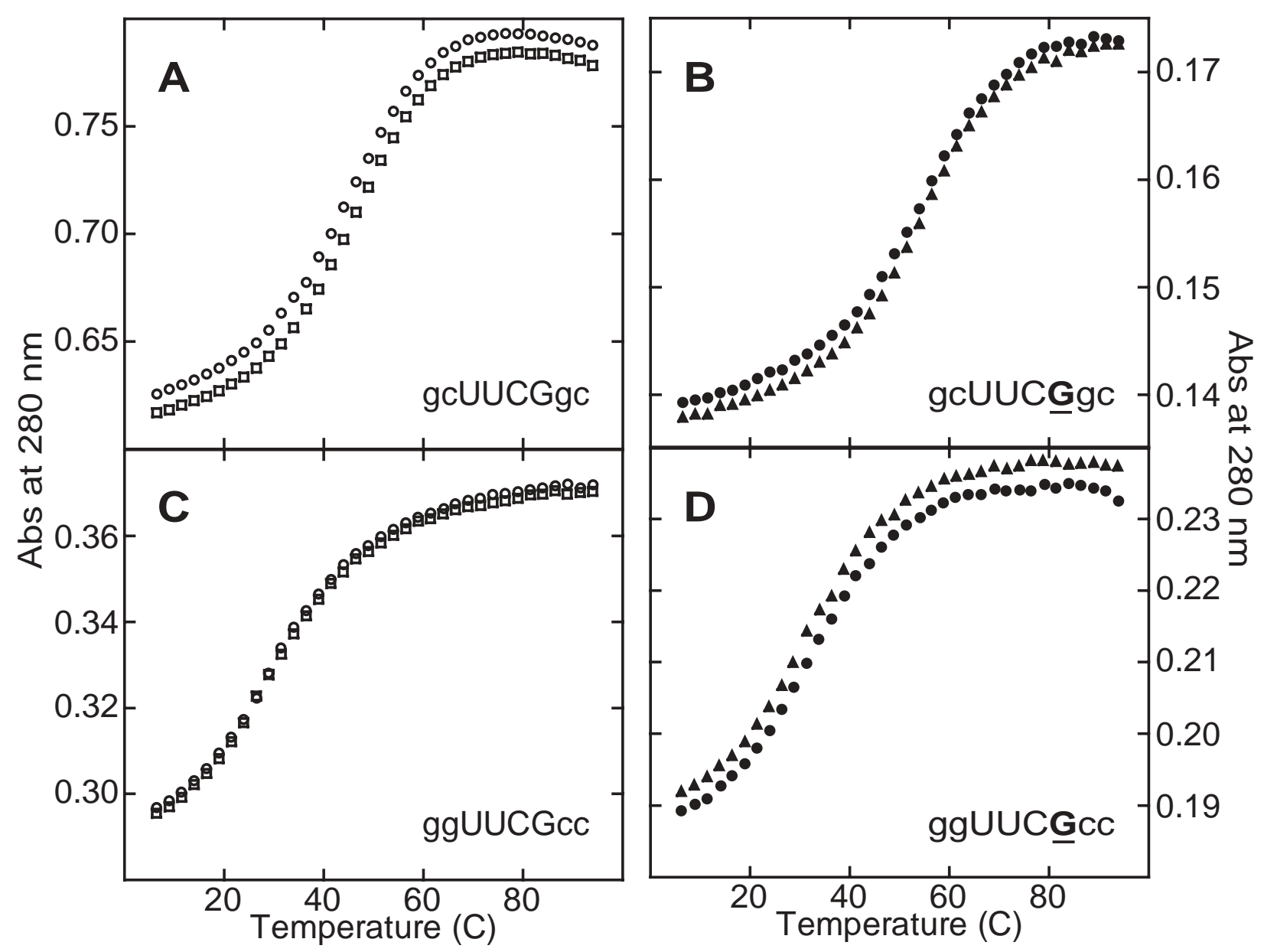

Supplemental Figure 1. Reversibility of UV thermal denaturation curves for unmodified and 8BrG-substituted gcUUCGgc and ggUUCGcc. Representative forward and reverse UV thermal denaturations of (A) gcUUCGgc $\left(\circ=5-95^{\circ} \mathrm{C}, \square=95-5^{\circ} \mathrm{C}\right),(\mathbf{B}) \operatorname{gcUUC} \underline{\operatorname{Gg}}\left(\bullet=5-95^{\circ} \mathrm{C}\right.$,

$\left.=95-5^{\circ} \mathrm{C}\right),(\mathbf{C}) \operatorname{ggUUCGcc}\left(\circ=5-95^{\circ} \mathrm{C}, \square=95-5^{\circ} \mathrm{C}\right)$, and $(\mathbf{D}) \operatorname{ggUUC} \underline{\operatorname{Gcc}}\left(\bullet=5-95^{\circ} \mathrm{C}, \boldsymbol{\Delta}=\right.$ 95-5 ${ }^{\circ} \mathrm{C}$ ) collected at $280 \mathrm{~nm}$ every $0.5{ }^{\circ} \mathrm{C}$ in $\mathrm{P}_{10} \mathrm{E}_{0.1}$; only every $5^{\text {th }}$ data point is shown for clarity. Similar sigmoidal transitions resulting from forward and reverse thermal denaturation demonstrates reversibility for the denaturation process and is consistent with two-state behavior. 

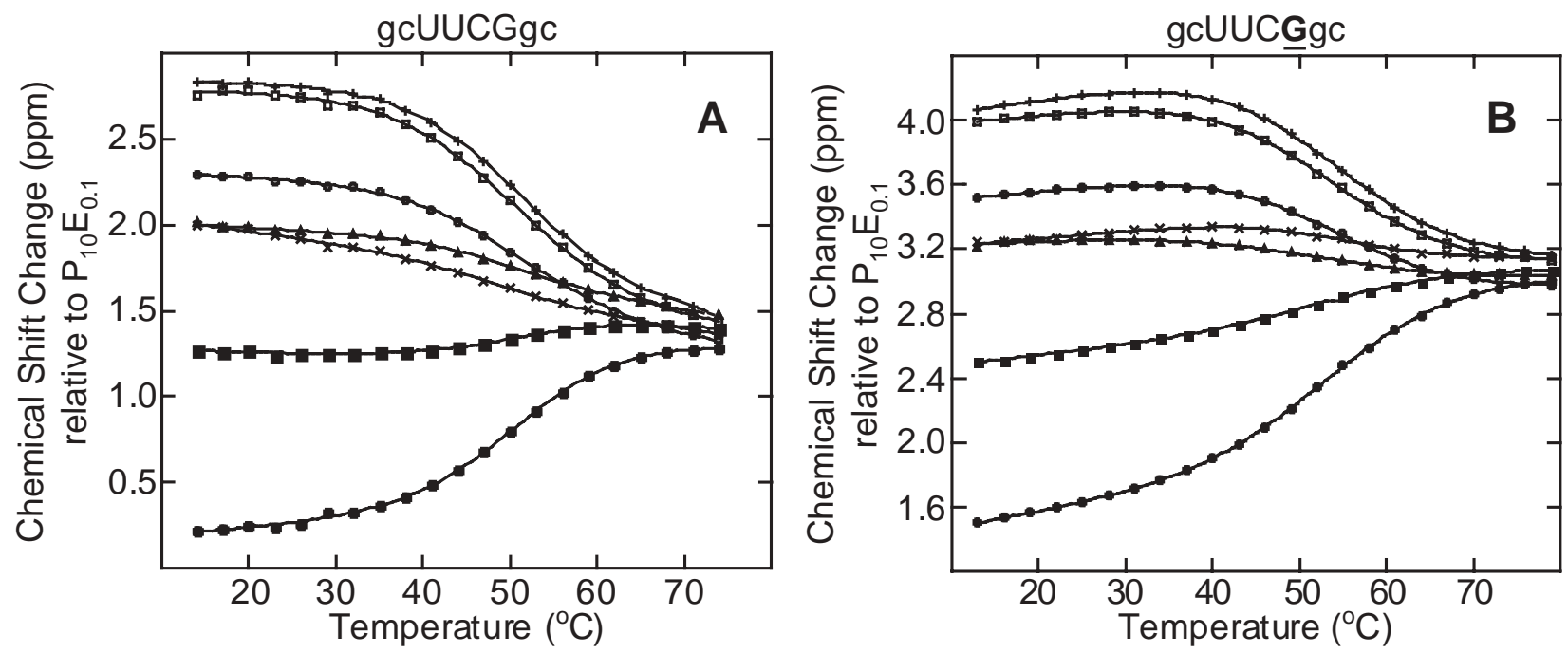

Supplemental Figure 2. NMR spectroscopic evidence for two-state unfolding of the gcUUCGgc and gcUUCGge hairpins. NMR chemical shift difference (relative to internal phosphate) as a function of temperature for seven resonances, which constitute the seven phosphorus atoms in each $8 \mathrm{nt}$ RNA. ${ }^{31} \mathrm{P}$ resonance as a function of temperature was collected every $3{ }^{\circ} \mathrm{C}$ from $14-74{ }^{\circ} \mathrm{C}$ for gcUUCGgc and $13-79{ }^{\circ} \mathrm{C}$ for gcUUCGgc. Nearly identical thermodynamic parameters obtained from independent fits of each sigmoidal transition (as compared to global fits with UV data, not shown) support the hairpin loop unfolding in concert with the stem, consistent with two-state denaturation and absence of any significant RNA backbone hydrolysis. It is worth noting that a $90^{\circ}$ counter-clockwise rotation of each panel provides for the observation of chemical shift as a function of temperature. Also, it is important to note that the resonance produced by the phosphate buffer is $\mathrm{pH}$-dependent, and a linear function of temperature with a positive slope. Thus, subtraction of this resonance resulted in flattened baselines for the sigmoidal transitions of RNA resonances, and addition of the phosphate buffer chemical shift to the chemical shift of any RNA phosphorus resonance will reconstitute the absolute chemical shift. 


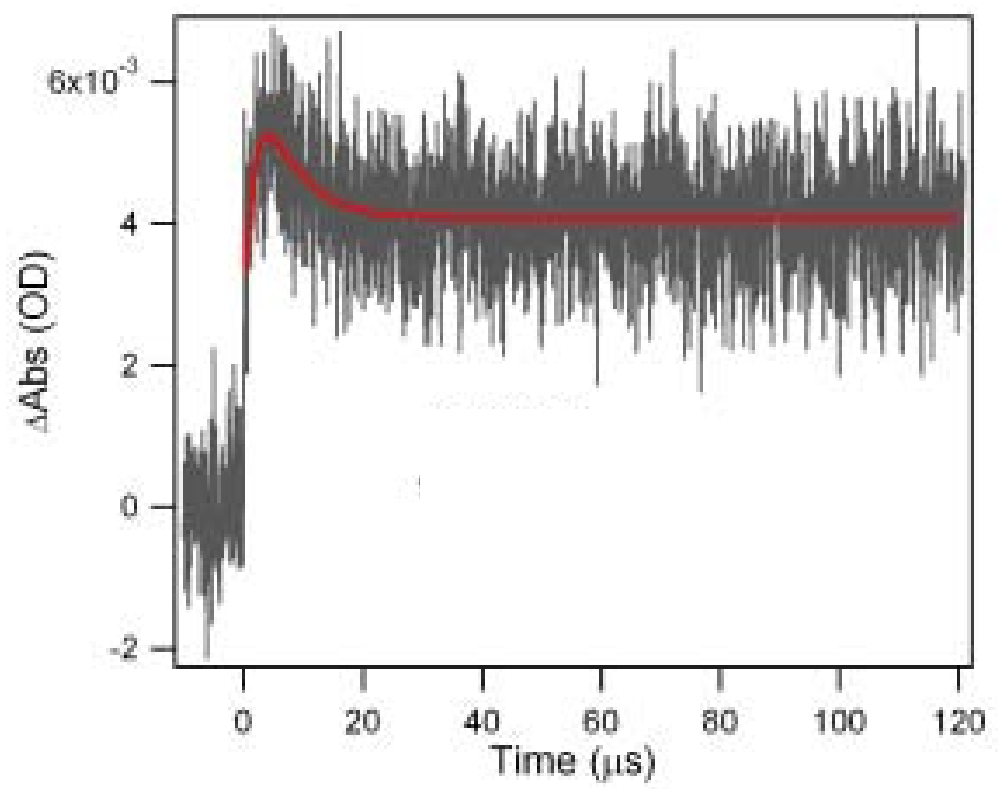

Supplemental Figure 3. Typical multiphase relaxation for a hairpin at $\mathrm{T}>>\mathrm{T}_{\mathrm{M}}$. At time 0, a T-jump was applied from 50 to $57.5^{\circ} \mathrm{C}$ to ggUUCGcc $\left(\mathrm{T}_{\mathrm{M}}=33.3{ }^{\circ} \mathrm{C}\right)$. Note that for the slow phase, absorbance decreases with time, and the amplitude is nearly as large as the amplitude of the fast phase. The relaxation trace was fit to a double exponential (red line). 